\title{
Corrigendum \\ Fluoxetine Alleviates Behavioral Depression while Decreasing Acetylcholine Release in the Nucleus Accumbens Shell
}

David T Chau, Pedro V Rada, Kay Kim, Rebecca A Kosloff and Bartley G Hoebel

Neuropsychopharmacology (2012) 37, 2346; doi:10.1038/npp.2012.96

Correction to: Neuropsychopharmacology (2011) 36, 1729-1737; doi:10.1038/npp.2011.54; published online 27 April 2011

In this article, the fluoxetine doses $(2,5$, and $7.5 \mathrm{mM})$ noted in Table 3 and in the Result section, under the heading 'Experiment 2: Local, Bilateral Fluoxetine Administration Increases Escape Efforts During the Swim Test', were incorrect. The correct fluoxetine doses used were $0.2,0.5$, and $0.75 \mathrm{mM}$, respectively. 